Original Research Article

\title{
Adverse drug reactions in the department of dermatology at a tertiary care hospital: a prospective study
}

\author{
Sujatha Sowmyanarayan $^{1}$, Rajeshwari K. A. ${ }^{2 *}$, Swati Banerjee ${ }^{1}$
}

\author{
${ }^{1}$ Department of Pharmacology, \\ ${ }^{2}$ Department of Dermatology, \\ East Point Medical College, \\ Bidrahalli Bangalore, \\ Karnataka, India
}

Received: 13 November 2017

Accepted: 04 December 2017

*Correspondence to:

Dr. Rajeshwari K.A.,

Email: mrskpbhat@yahoo.co.in

Copyright: (C) the author(s), publisher and licensee Medip Academy. This is an openaccess article distributed under the terms of the Creative Commons Attribution NonCommercial License, which permits unrestricted noncommercial use, distribution, and reproduction in any medium, provided the original work is properly cited.

\begin{abstract}
Background: To study cutaneous adverse drug reactions with regard to their clinical pattern. etiology, causality and severity.

Methods: It was a prospective study undertaken in a 300 bedded tertiary care hospital. Patients with cutaneous ADRs presenting in Dermatology OPD were studied. Causality and severity of the adverse drug reactions were analysed and other parameters such as gender wise distribution of the ADRs and types of ADR were studied.
\end{abstract}

Results: 35 cases of ADRs were enrolled for the study in the duration of Sept.2016 to May 2017. The majority of the patients were in the age group of 2130 years $(37.14 \%)$. The most common CADRs were Acne vulgaris $(22.86 \%)$, followed by Fixed Drug eruption $(11.43 \%)$ and Tinea cruris $(8.57 \%)$. The most common class of drugs causing ADRs were topical steroids $(64 \%)$, followed by non-steroidal anti-inflammatory drugs (14.29\%).

Conclusions: Female preponderance was seen. Topical steroids were the most offending drug followed by Diclofenac Sodium, the analgesic. Causality assessment showed a high score of Certain category. These variations may be explained by variations in drug usage patterns. The knowledge of the adverse drug reactions and the drugs causing them is essential for the clinician so that the choice of drug therapy can be made keeping these adverse drug reactions in mind.

Keywords: Adverse drug reactions, Causality, Clinical pattern, Drugs causing ADRs, Severity

\section{INTRODUCTION}

With the advent of newer drugs by the day it has become absolutely essential to monitor the adverse reactions due to these drugs. Adverse drug reactions are the leading cause of mortality and morbidity in health care and have a significant impact on health care resources. ${ }^{1}$ Cutaneous drug are one of the most common types of adverse reactions to drug therapy. Almost any drug can cause a skin reaction. The WHO defines ADR as "Any reaction which is noxious and unintended and which occurs in man due to use of a drug for the prevention, treatment or diagnosis of disease". ${ }^{2}$ An adverse cutaneous drug reaction caused by a drug is any undesirable change in the structure or function of the skin, it's appendages or mucous membranes and it encompasses all adverse events related to drug eruption, regardless of etiology. ${ }^{3}$ Although many of the skin reactions are not serious, some are lifethreatening such as Angio-edema, Stevens-Johnson Syndrome and Toxic Epidermal Necrolysis. ${ }^{4}$

Studies have found the overall incidence of adverse drug reactions in skin in developed countries as 1-3\% and in the developing countries it is higher between $2-5 \% .^{1,5} 5$ $10 \%$ of hospital admissions are due to drug related problems, in which $50 \%$ are avoidable. ${ }^{6}$ Adverse drug reactions constitute a significant economic burden for 
hospitals. Hospital based adverse drug reaction monitoring and reporting programmes aim to identify and quantify the risks associated with the use of drugs provided in a hospital setting. 7A study conducted at four hospitals in South Africa showed that $2.9 \%$ and $16 \%$ of the mortality were due to ADRs and ADR related complications respectively ${ }^{2}$. ADR reporting is crucial because two independent studies in India have concluded that some patient groups are at a particular risk of developing ADRs, for example infants, those using cardiovascular drugs and patients receiving four or more types of medication..$^{89}$

Adverse reactions are recognized hazards of drug therapy. Early detection, evaluation and monitoring of Adverse drug reactions are essential to reduce harm to patients and thus improve public health. With the increase in the production of various pharmaceutical products, newer drugs are being introduced every year. ${ }^{10}$ Hence it has become essential to monitor the effects and adverse drug reactions pertaining to these drugs. We undertook this study to detect and analyse ADRs in the outpatient department of Dermatology. Developing awareness in patients and healthcare professionals will help in reducing the adverse drug reactions, the suffering due to the adverse drug reaction and socio-economic impact.

Pharmacogenomic markers have been identified for a growing number of drugs for serious ADRs and implementation of Pharmacogenomic testing has been advances as a means to prevent the occurrence of some of the ADRs. ${ }^{11} \mathrm{An}$ example is the recommendation for pharmacogenetic testing of HLA B 1502 allele before prescribing carbamazepine as risk stratification for prevention of severe skin allergic reactions, leading to a significant drop in cases of carbamazepine-induced Steven-Johnson syndrome and toxic epidermal necrolysis. In this way examining ADRs for association with pharmacogenomic markers would provide an additional layer of information on the preventability of ADRs.

The Objective of the study was to find out the incidence of adverse drug reactions (ADR) and to study various aspects of these ADRs in patients of Dermatology department of East Point Medical College and Hospital, a tertiary care hospital. The aspects of ADR included patient demographics, causality, severity, type of reaction and drugs commonly causing ADR. The present study was conducted based on the cutaneous adverse drug reactions reported between September 2016 and May 2017.

\section{METHODS}

This was a prospective, observational, descriptive study carried out at the department of Dermatology, East Point Medical College and Hospital. The hospital is a 300 bedded tertiary care hospital. The study was carried out for a period of eight months. All the patients who reported in the Dermatology OPD were screened and patients with suspected cutaneous ADR presenting primarily in the Dermatology OPD or referred from other departments of the hospital during the study period were included in the study.

Table 1: WHO UMC causality assessment scale the causality assessment of the adverse drug reactions was done using this scale. ${ }^{12}$

\begin{tabular}{|c|c|}
\hline Causality term & Assessment criteria \\
\hline Certain & $\begin{array}{l}\text { Event or laboratory test abnormality, with plausible time relationship to drug intake } \\
\text { - } \quad \text { Cannot be explained by disease or other drugs } \\
\text { - } \quad \text { Response to withdrawal plausible (pharmacologically, pathologically) } \\
\text { Event definitive pharmacologically or phenomenologically (ie.an objective and specific medical } \\
\text { disorder or a recognized pharmacologic phenomenon) } \\
\text { - } \quad \text { Re-challenge satisfactory, if necessary }\end{array}$ \\
\hline Probable/likely & $\begin{array}{ll}\text { - } & \text { Event or laboratory test abnormality, with reasonable time relationship to drug intake } \\
\text { - } & \text { Unlikely to be attributed to disease or other drugs } \\
\text { - } & \text { Response to withdrawal clinically reasonable } \\
\text { - } & \text { Re-challenge not required }\end{array}$ \\
\hline Possible & $\begin{array}{l}\text { Event or laboratory test abnormality, with reasonable time relationship to drug intake } \\
\text { - } \quad \text { Could also be explained by disease or other drugs } \\
\text { - } \quad \text { formation on drug withdrawal may be lacking or unclear }\end{array}$ \\
\hline Unlikely & $\begin{array}{l}\text { - Event or laboratory test abnormality with a time relationship to drug intake that makes a relationship } \\
\text { improbable (but not impossible) }\end{array}$ \\
\hline $\begin{array}{l}\text { Conditional/ } \\
\text { unclassified }\end{array}$ & $\begin{array}{l}\text { Event or laboratory test abnormality } \\
\text { - } \quad \text { More data for proper assessment needed or } \\
\text { - }\end{array}$ \\
\hline $\begin{array}{l}\text { Unassessable/ } \\
\text { Unclassifiable }\end{array}$ & $\begin{array}{l}\text { - } \quad \text { Report suggesting an adverse drug reaction } \\
\text { - } \quad \text { Cannot be judged because information is insufficient or contradictory } \\
\text { - } \quad \text { Data cannot be supplemented or verified }\end{array}$ \\
\hline
\end{tabular}


The diagnosis of the cutaneous adverse drug reaction was based on the history of drug exposure and clinical findings and was done by the consultant Dermatologist. The parameters were recorded on an ADR monitoring form which included Demographic characteristics of the patient, type of ADR, drug causing ADR, duration of exposure, causality, severity, treatment for the ADR. Causality was assessed based on the WHO Causality Assessment Scale and severity was assessed based on the Hartwig and Siegel Scale.

\section{Severity assessment by the modified Hartwig and Siegel} severity assessment scale ${ }^{13}$

Severity of the adverse drug reactions was assessed using the modified Hartwig and Siegel severity assessment scale. The severity is broadly categorized into mild, moderate and severe for each ADR. The suspected ADR is mild when "an ADR occurs but requires no change in treatment with the suspected drug. The ADR requires that treatment with suspected drug be held, discontinued, or otherwise changed. No antidote or other treatment was required. The suspected ADR is moderate when the ADR requires treatment with the suspected drug be held, discontinued or otherwise changed and or an antidote or other treatment was required. No increase in length of stay(LOS) or any level 3 ADR that increases LOS by at least one day or the ADR was the reason for the admission.

Table 2: Gender wise distribution of patients.

\begin{tabular}{|lll|}
\hline Gender & No. of patients & Percentage \\
\hline Males & 12 & 34.28 \\
\hline Females & 23 & 65.71 \\
\hline
\end{tabular}

\section{Age wise distribution of patients}

The majority of the patients belonged to the age group of 21-30 years $(37.14 \%)$, followed by $31-40$ years $(20 \%)$, followed by $41-50$ years $(14.28 \%)$. The least number of patients were seen in the age group of $0-10$ years $(2.9 \%)$.

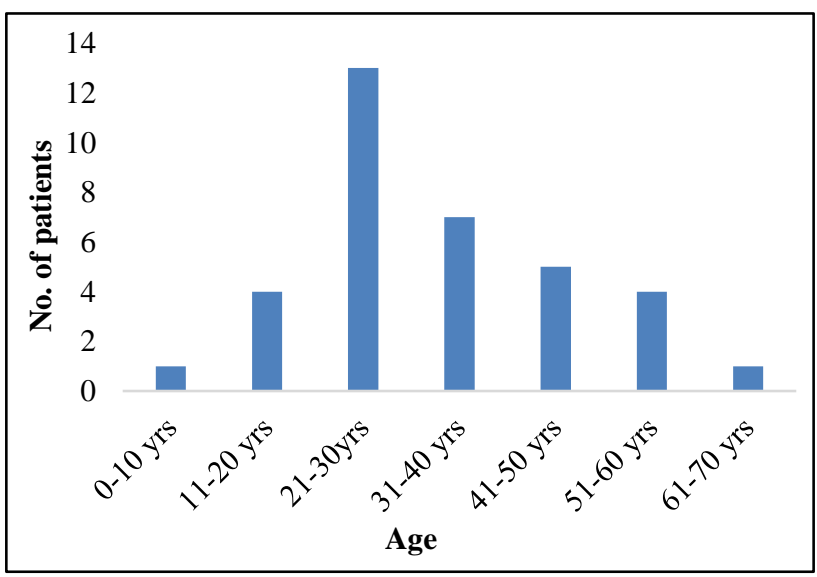

Figure 1: Age wise distribution of patients.

\section{Clinical pattern of ADRs}

The most common cutaneous ADR observed was acne vulgaris $(22.86 \%)$ and generalized skin rash $(22.86 \%)$ followed by fixed drug eruption $(11.43 \%)$. The other cutaneous ADRs seen included Tinea cruris (8.57\%), melasma $(5.71 \%)$, chronic urticarial $(2.9 \%)$, tinea incognita $(2.9 \%)$, contact dermatitis $(2.9 \%)$, toxic epidermal necrolysis $(2.9 \%)$, pruritic $(2.9 \%)$, atopic dermatitis $(2.9 \%)$, vasculitis $(2.9 \%)$, cushingoid features $(2.9 \%)$ and topical atrophy $(2.9 \%)$.

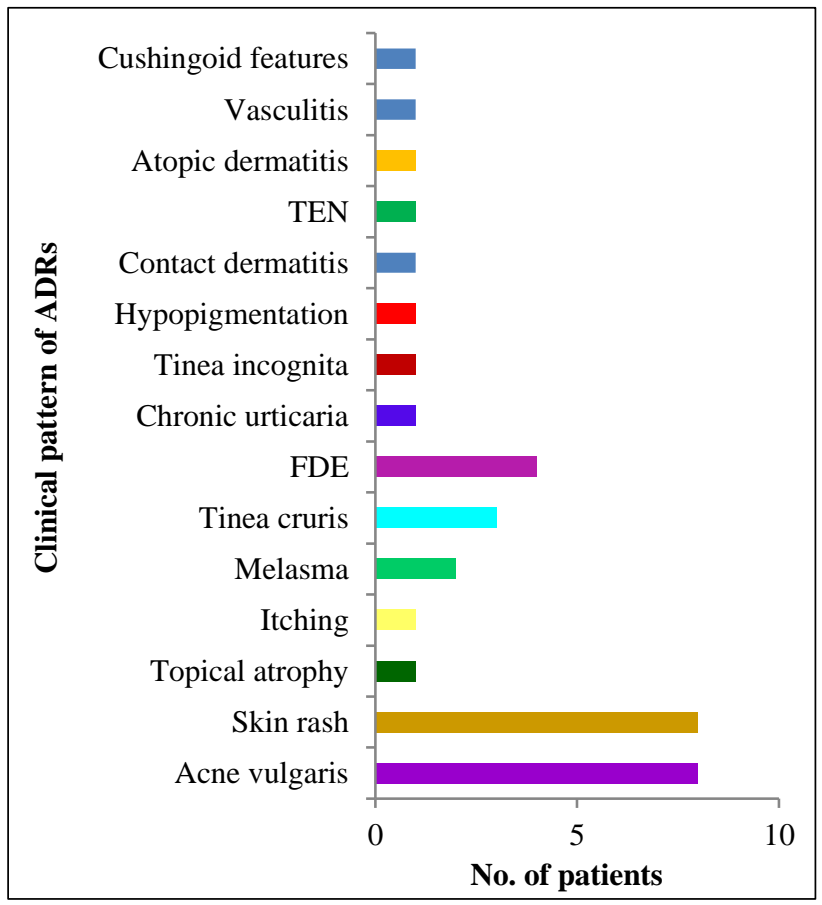

Figure 2: Clinical pattern of ADRs.

\section{Drugs causing adverse drug reactions}

The most common group of drugs causing ADR was Topical steroids $(64 \%)$ followed by analgesics/antiinflammatory/anti-pyretic $(14.3 \%)$ and then antibiotics (8.6\%). Antifungal, anti-epileptic, statins and polypharmacy accounted for about $2.9 \%$ each of CADRs.

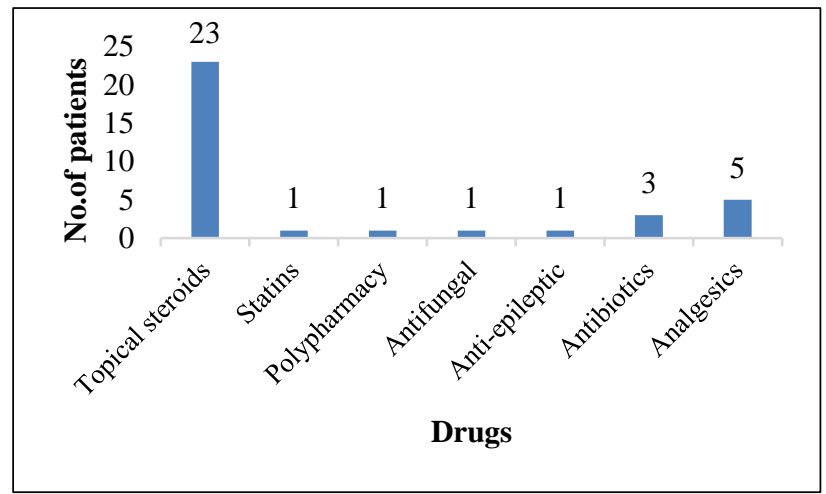

Figure 3: Drugs causing ADRs. 


\section{Causality assessment}

Causality assessment was done using the WHO UMC Causality Assessment Scale. 35 cases of cutaneous ADRs were analysed. Based on the assessment, 27 (77.14\%) cases scored Certain, 7 (20\%) cases were in the Probable category and one case $(2.9 \%)$ was in the Possible category (Table 3).

Table 3: Causality.

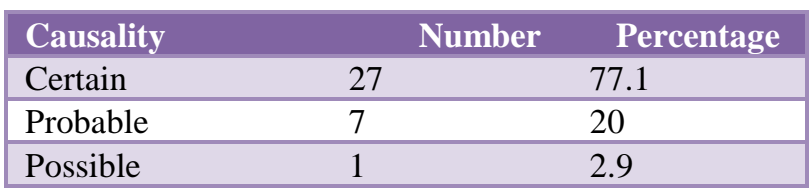

Unlikely, conditional and unassessable cases were excluded from the study. The severity of the reactions was assessed using the Modified Hartwig and Siegel Scale.28 (80\%) cases were of Moderate severity,5 (14.3\%)cases were of Mild severity and $2(5.71 \%$ ) cases were graded as Severe (Table 4).

\section{Severity}

The duration of exposure was varied for different drugs, but for the topical steroids the minimum period of exposure was one week, and the maximum was ten years. Out of the 23 cases of topical steroid causing ADR 17 cases had a minimum period of exposure of one month.

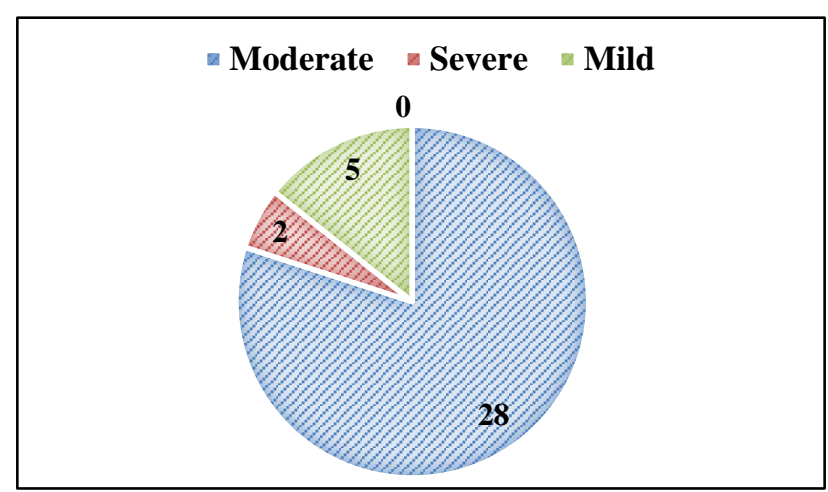

Figure 3: Severity of ADRs.

Table 4: Severity of ADR.

\begin{tabular}{|lll|}
\hline Category & Number & Percentage \\
\hline Mild & 5 & 14.28 \\
\hline Moderate & 28 & 80 \\
\hline Severe & 2 & 5.71 \\
\hline
\end{tabular}

\section{DISCUSSION}

Cutaneous adverse drug reactions have a variety of clinical presentations. In the present study a total of 35 adverse drug reactions were studied. Out of these $23(65.7 \%)$ were females and $12(34.28 \%)$ were males. This is similar to the study, and also in a study conducted in a tertiary Care Hospital of South India conducted by Pudukadan D. ${ }^{3,14}$ The maximum number of patients were in the age group of 21-30 years $(37.14 \%)$ followed by $31-40$ years $(20 \%)$, which is in accordance with another study that also reported similar observations. ${ }^{15}$

In present study the most common adverse drug reactions were acne vulgaris $(22.86 \%)$ and generalised skin rash $(22.86 \%)$. The acne vulgaris was predominantly due the abuse of topical steroids. The topical steroids are available over the counter and these patients have developed ADR. This means that without a prescription topical steroid should not be prescribed.

There was only one case of severe ADR which was TEN due to Ciprofloxacin. The most common group of drugs causing ADR was Topical Steroids (64\%) followed by NSAIDs (14.3\%) which is different from other studies in which antimicrobials or antibiotics have been the most common offending agent. In this study the WHO-UMC Causality Assessment Scale was used to categorise the ADRs as Certain, Probable or Possible. There was a high incidence of cases in the certain (27) category as the patients repeatedly applied the topical steroid and hence the repeated application can be considered as re-challenge although re-challenge was not done due to ethical reasons. In other studies, such as the one carried out by Harsha R the majority of the ADRs were in the probable category. ${ }^{16}$

Out of 35 cases, 28 cases were in the moderate category which is in accordance with another study. ${ }^{7,17}$ Long term exposure to topical steroids caused adverse drug reactions with the minimum period of exposure being one week.

\section{CONCLUSION}

Monitoring of adverse drug reactions is extremely important as they are a cause for morbidity and mortality. This study has shown that the over the counter medications have been a cause for the majority of the ADRs in the Dermatology Department. The variations in results as compared to other studies is due to differences in drug usage patterns and short duration of the study. In present study there have been a number of cases of topical steroid abuse which we would like to highlight. This study is a preliminary study to initiate a culture of ADR reporting among health care professionals and to develop an Adverse Drug Reaction Monitoring Centre.

\section{ACKNOWLEDGEMENTS}

Authors would like to thank Department of Dermatology for helping them to conduct this study.

\section{Funding: No funding sources}

Conflict of interest: None declared

Ethical approval: The study was approved by the Institutional Ethics Committee 


\section{REFERENCES}

1. Prajapati K, Desai M, Shah S, Panchal J, Kapadia J, Dikshit R. An analysis of serious adverse drug reactions at a tertiary care teaching hospital. Perspectives in Clin Res. 2016;7(4):181-6.

2. Amin MN, Khan TM, Dewan SMR, Islam MS, Moghal MR, Ming LC. Cross-sectional study exploring barriers to adverse drug reactions reporting in Community pharmacy settings in Dhaka, Bangladesh. BMJ. 2016;6(8):564-9.

3. Verma R, Tiwari S, Gupta CM, Verma N. Cutaneous adverse drug reactions- A study of clinical patterns, causality, severity and preventability. J Dent Med Sci. 2014;1:102-9.

4. Lamani VL, Ratnakar JS, Kotinatot BC, Bhusan A. Study of cutaneous adverse drug reactions in a tertiary care teaching hospital. Int J Bas App Med Sci. 2015;5:71-4.

5. Sharma R, Dogra D, Dogra N. A study of cutaneous adverse drug reactions at a tertiary center in Jammu, India. Ind Dermatol On J. 2015;6(3):168.

6. Nivya K, Kiran VS, Ragoo N, Jayaprakash B, Sekhar MS. Systemic review on drug related hospital admissions- A pubmed based search. Saudi Pharma J. 2015;23(1):1-8.

7. Lobo MG, PinheiroSM, CastroJG, Momente VG, Pranchevicius MC. Adverse Drug Reaction Monitoring: Support for Pharmacovigilance at a tertiary care hospital in Northern Brazil BMC Pharmacol. Toxicol. 2013;14:5.

8. Kurian J, Mathew J, Sowjanya K. Adverse Drug Reactions in hospitalized paediatric patients: a prospective observational study. Ind $\mathbf{J}$ Paediat. 2016;83:414-9.

9. Palaniappan M, Selvarajan S, George M. Pattern of Adverse Drug Reactions reported with cardiovascular drugs in a tertiary care teaching hospital. J Clin Diagn Res. 2015;9:FC01-4.

10. Shamna M, Dilip C, Ajmal M, Linu Mohan P, Shinu C, Jafer C, et al. prospective study on Adverse Drug Reactions of antibiotics in a tertiary care hospital Saudi Pharm J. 2014;22(4):303-8.

11. Chang SL, AngX, SaniLL, Ng HY, Winther MD, Liu JJ, Brunham LR. Prevalence and characteristics of adverse drug reactions at admission to hospital: a prospective observational study Br J Clin Pharmacol. 2016;82(6):1636-46.

12. Srinivasan R, Ramya G. Adverse drug reactionCausality assessment. IJRPC. 2011;1:606-12.

13. Hartwig SC, Siegel J, Schneider PJ. Preventability and severity assessment in reporting adverse drug reactions. Am J Hosp Pharm. 1992;49:2229-32.

14. Pudukadan D, Thappa DM. Adverse cutaneous drug reactions: Clinica patterns and causative agents in a tertiary care centre in South India. Indian J Dermatol Venereol Leprol. 2008;74:80.

15. Sharma VK, Sethuraman G, Kumar B. Cutaneous adverse drug reactions: Clinical pattern and causative agents A six year series from Chandigarh. Ind $\mathbf{J}$ Postgrad Med. 2001;47:95-9.

16. Ramakrishnaiah H, Krishnaiah V, Pundarikaksha HP, Ramakrishna V. A prospective study on adverse drug reactions in outpatients and inpatients of Medicine Department in a Tertiary care hospital. Int J Basic Clin Pharmacol. 2015;4(3):515-21.

Cite this article as: Sowmyanarayan $\mathrm{S}$, Rajeshwari $\mathrm{KA}$, Banerjee $\mathrm{S}$. Adverse drug reactions in the department of dermatology at a tertiary care hospital: a prospective study. Int $\mathrm{J}$ Basic Clin Pharmacol 2018;7:162-6. 